\title{
Performance Evaluation in the Process of Motivation: An Application of Expectancy Theory
}

\author{
Cynthia L. Tomovic \\ Purdue University
}

\begin{abstract}
Just because employees have the ability to do a good job does not mean that they will perform satisfactorily. Effective performance is a function of an employee's willingness to exert high energy levels - their motivation. The purpose of this paper is to briefly present how a performance evaluation system can impact the motivational process. Specifically, the impact of performance evaluation systems is discussed in terms of needing to manage the links between effort and performance and performance to rewards as defined in the expectancy theory of motivation.
\end{abstract}

\section{Introduction}

Employees need to feel confident that if they exert effort within their capabilities that it will result in a better performance as defined by the criteria used to measure their performance. In addition, employees must feel confident that if they perform as being asked, the reward that follows will be of value to them personally. If people do not see that effort leads to performance, and that performance leads to valued rewards, the potential motivational aspects of conducting a performance evaluation are lost. While the logic of the above statement may seem simple enough, the execution is difficult. In this paper, performance evaluation is discussed in terms of its role in the motivation process and examples of typically encountered problems are shared.

\section{Expectancy Theory}

Today, expectancy theory 1 is one of the most widely accepted explanations of motivation. After almost forty years since its introduction, evidence suggests that, overall, expectancy theory works 2.

Essentially, expectancy theory focuses on three relationships.

\section{Expectancy Theory}

\begin{tabular}{|c|c|c|c|c|c|}
\hline Individual & Individual & & Organizat & & Personal \\
\hline Effort $\longleftrightarrow$ & Performance & $\Longrightarrow$ & Rewards & $\Longrightarrow$ & Goals \\
\hline $\mathrm{R} 1$ & & $\mathrm{R} 2$ & & R3 & \\
\hline
\end{tabular}


R1.Effort-performance relationship. The probability that a given amount of effort will lead to a particular performance, as perceived by the individual.

R2.Performance-rewards relationship. The probability that performing at a particular level will lead to attaining the desired reward, as perceived by the individual.

R3.Reward-personal goal relationship. The probability that receiving an organizational reward will lead to satisfying a personal goal, as perceived by the individual.

In the case of each relationship, it is the individual's perception that drives the motivation process. Thus, it is the manager's responsibility to create a relatively predictable environment from which an individual can calculate the probability of a particular outcome within each relationship. Managers can best create and maintain that environment through the effective development and use of a viable performance management system.

\section{Application of Expectancy Theory as it Relates to Performance Management}

Appraising an employee's performance is an important managerial responsibility. The results of a performance appraisal are used in such personnel decisions as promotions and terminations; where to spend training dollars; and where to allocate pay raises 3 .

Effort-performance relationship. With regard to understanding and applying the effortperformance relationship as defined in expectancy theory, it would be the manager's responsibility to clarify exactly what behaviors are valued by the organization since it is these behaviors that lead to the desired organizational performance. Therefore, as part of the performance evaluation system, the manager would need to define and share with the employees, hopefully in advance of actually conducting a performance appraisal, what behaviors are valued and why. In this manner, not only could a manager conduct an evaluation of the current year's performance, but also he or she could help an employee set future goals that would address any apparent shortcomings.

It is important that a manager recognize that if an employee believes that his or her skill level is deficient, and thus would believe they could not attain the desired performance, the employee is not likely to execute the necessary effort. Equally, the level of employee trust in the objectivity of the performance management system can affect the level of the effort exerted. If, for example, an employee believes that non-behavioral factors such as loyalty or camaraderie are being rewarded over efforts that lead to improved performance, efforts may be compromised. Likewise, if an employee believes that he or she is being unfairly discriminated against, they are not likely to expend the necessary effort to attain the desired performance (in less of course, they are out to "show you"). In each of the examples cited, lack of requisite skills, lack of trust in the system, or feelings of discrimination may result in low motivation and the employee's belief that regardless of the effort they expend, they will receive a low performance appraisal. In effect, they surmise that their level of effort is meaningless and consequently truncate their effort. 
Performance-reward relationship. Regarding the performance-reward relationship, it would be the manager's responsibility to clarify exactly what organizational rewards would be forth coming, given that a particular level of performance was attained. It would also be the manager's responsibility to maintain the integrity of the system by safeguarding the potential devastating affects produced if a promised reward is not delivered. A breech of trust is difficult to recover from.

In many organizations, however, this relationship proves to be quite weak since, often times, organizations reward employees for more than just their performance. Again, the practice of rewarding employees for non-behavioral factors such as seniority or cooperativeness does not lend any credibility to a behaviorally based system. According to expectancy theory, an employee's level of motivation is affected by the degree to which they believe rewards are truly anchored in behaviors that translate into desired organizational performance.

Reward-personal goal relationship. Within the expectancy theory of motivation, while it would be the manager's responsibility to help clarify the link between effort and performance, and performance to reward, with regard to the reward-personal goal relationship, what a manager does within the context of conducting a performance review may have little effect. In essence, if the organizational rewards that a manager has access to holds little or no value to an individual employee, because it does not further the employee's attainment of his or her own personal goal, then the manager can do little to improve the motivation of the employee.

In this case, the manager must spend the time required to determine the personal goal of each employee and to ascertain whether they have the necessary organizational rewards at their disposal that, if rewarded, would lead to fulfilling an employee's personal goal. In essence, the job of the manager in this case would be to determine the motivational effects of the different rewards available. Recognize, however, that the value of any one reward is situation specific. What may be of value under one set of conditions is likely to change over time.

\section{Closing}

In summary, the key to understanding and applying expectancy theory in the context of creating an effective performance management system is to understand that managers are responsible for determining each individual employee's goals; that it is management's responsibility to actively clarify the links between effort and performance, and performance and rewards for each employee; and that it is management's responsibility to determine whether the rewards available will lead to individual employee goal attainment and satisfaction. While it was stated earlier that overall evidence supports the validity of expectancy theory, it has been determined that expectancy theory is particularly applicable in explaining employee productivity in complex organizations where employees have a greater amount of job discretion 4 . It is also noted that for those individuals who exhibit a high internally driven need for achievement, the drive to excel, to achieve in relation to a set of standards 4 , that they are less motivated by an organization's assessment of their performance. Thus, they are less concerned with the effortperformance, performance-rewards, and rewards-goal relationships. "Hard chargers" are typically motivated by personal responsibility, feedback, and moderate risks. On the other hand, 
not everyone wants a challenging job. While a portion of the labor force seeks interesting and challenging jobs, you cannot generalize the entire population.

Reiterating, the application of expectancy theory in the context of developing an effective performance management system suggests that in order for effort to lead to good performance, individuals must believe that they have the requisite ability to perform, and that the appraisal system encourages the use of objective performance measures. Given these conditions, if the rewards available are deemed valuable by individual employees in helping them to attain their own personal goals, expectancy theory predicts that most employees will exert high levels of effort. According to Caudron 6, if you want to get the most out of people, stop looking for the super individual...time would be better spent, and employee motivation would likely increase, if you discern what is important to each individual... and ensure that effort is linked to performance and that rewards are linked to performance.

\section{Bibliography}

1. Vroom, V.H. Work and Motivation. New York: John Wiley, 1964.

2. See for example, Muchinsky, P.M. A comparison of within- and across-subjects analyses of the expectancyvalence model for predicting effort, Academy of Management Journal, March 1977, pp. 154-158. Wanous, J.P., Keon, T.L., \& Latack, J.C. Expectancy theory and occupational/organizational choices: A review and test, Organizational Behavior and Human Performance, October 1983, pp. 66-86.

3. Byrne, J.A. Deliver - or else, Business Week, Marc 27, 1996, p. 36.

4. McClelland, D.C. The Achieving Society. New York: Van Norstrand Reinhold, 1961.

5. Shellenbarger, S. Data gap, Wall Street Journal, June 21, 1993, p. 6.

6. Caudron, S. The top 20 ways to motivate employees, Industry Week, April 3, 1995, p. 14.

\section{CYNTHIA L. TOMOVIC}

Dr. Cynthia L. Tomovic is a professor and acting department head in the Department of Organizational Leadership and Supervision, Purdue University. In addition to her administrative duties, she teaches courses in organizational behavior and human resource management. She has published extensively on issues pertaining to quality improvement and assessment in higher education. 